\title{
Design Strategies for Reorganizing the Public Realm of a Neighbourhood Unit: The Case of the Modern Housing Complex, Manimajra, Chandigarh
}

\author{
KANIKA BANSAL \\ Associate Professor, Chitkara University, Punjab - 140401, India \\ E-mail: kanikabansal80@gmail.com
}

Received: April 28 $8^{\text {th }}, 2014$ | Revised: January 19 ${ }^{\text {th }}, 2015$ | Accepted: January $20^{\text {th }}, 2015$

Published online: January 21, 2015

The Author(s) 2015. This article is published with open access at www.chitkara.edu.in/publications

Abstract: The Public Realm, an interface between the public and the private, is a vital aspect of the built environment that helps to give a city its identity. Despite being a highly significant contributor towards shaping the urban life and the quality of urban spaces, the fact remains that the concept and idea of meaningful public realm remains largely ignored, especially within neighbourhoods with their series of unmaintained and misused public spaces. Such is the case of the Modern Housing Complex at Manimajra, Chandigarh, where the planned open spaces and parks have been increasingly converted into parking lots, garbage yards with uncontrolled vegetation, or spaces that promote antisocial activities, all of which together affect the livability and attractiveness of the 'model' colony.'

This paper is based on a study of Manimajra's Modern Housing Complex, that was undertaken in 2012-13. The objective was to focus on the public realm and to devise design strategies for a livable neighbourhood through a community-based vision for an improved, high quality Public Realm making the neighbourhood more vibrant, safe and a truly liveable place. The study was based on an understanding of how the physical pattern and organization of a neighborhood influences perception and understanding of public places, multiple forms in which public places are manifested, different ways in which public places are understood, and various manners in which public places are used. The study reinforced the notion that the design, condition and quality of the neighbourhood streets and spaces have a major impact on the quality of its inhabitants' life, and their careful designing and quality development can help to create successful public places.

Keywords: Public realm, neighbourhood concept, streetscape, underutilized spaces

\section{INTRODUCTION: PUBLIC REALM AND ITS SIGNIFICANCE}

This paper is based on the premise that "Cities are about people." We engage with the public face of the city every day - with roads, streets, lanes, pavements, parks and piazzas, and all other publicly accessible spaces between buildings, including the neglected voids in the urban matrix. This is the 'public realm', free to use by everyone, and experienced by the everyday user, regardless of age

Creative Space Vol. 2, No. 2, January 2015 pp. 157-182

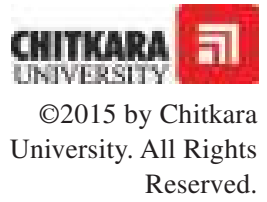


or social status, as an essential part of everyday life. This is why public realm is so important and deserves such careful consideration and development.

The Public Realm is a vital aspect of the built environment that helps to gives the territory of a community its individual identity. A quality public realm enables fulfilment of the socio-economic potential of a place/ city/town/ community. It facilitates 're-positioning/re-imaging' of a neighbourhood and transforms places into high quality places in which people enjoy to live, visit and invest, enhancing their 'sense of civic pride' and 'sense of place' and, in the process ensuring long-term Vitality, Viability and Vibrancy of a place.

The public realm within a neighbourhood should feature quality open spaces of various sizes and programming types, as well as opportunities for public activity that invite people to gather and socialize. It provides an approach to movement networks, street design and open space control to support communities within neighbourhoods, creating a healthy and safe and a congenial environment where children may safely play near their house and elderly get place to interact and rejuvenate in the evenings.

\section{THE MODERN HOUSING COMPLEX AT MANIMAJRA, CHANDIGARH}

The Modern Housing Complex - one of the earliest Group Housing Schemes in Chandigarh - lies to the south west of the town of Manimajra and on the north-eastern edge of the Chandigarh city (Fig. 1, 2). The area is bordered by the road V1 connecting to the National Highway, NH-22, on the northeastern edge of the city. An large vacant patch defines the southern and the south eastern boundary of the Study Area along the road leading to the Rajiv Gandhi Technology Park.

Built in three phases, the neighbourhood was planned as a high-density, primarily residential community, with a range of building types including midrise apartments in Phase -I and Phase II and independent, terraced houses in the Phase-III. Phase-I and II occupy about 60 acres of land acquired by the Chandigarh Administration in 1989. It accommodates 2200 dwelling units of various categories in the form of four storeyed flats, designed and constructed by the Chandigarh Housing Board. The flats within each category number as follows - Category I (243 sq.m): 480 nos.; Category II (162 sq.m): 384 nos.; Category III (122 sq. m.): 456 nos.; Category IV (90 sq. m.): 960 nos. The Phase-III covers a land measuring 9.63 acres and has 600 'High Income Group' terraced dwelling units on independent plots.

Observations on the built form of the study area reveal a mixture of building types and heights. Phase I and Phase II are dominated by a series of four storeyed apartments, each block of six apartments grouped around a central 
Figure 1: Location of Manimajra on the north-eastern edge of Chandigarh. (Image Source: Adapted by Author from the Google Earth Image downloaded on 10.11.2012).
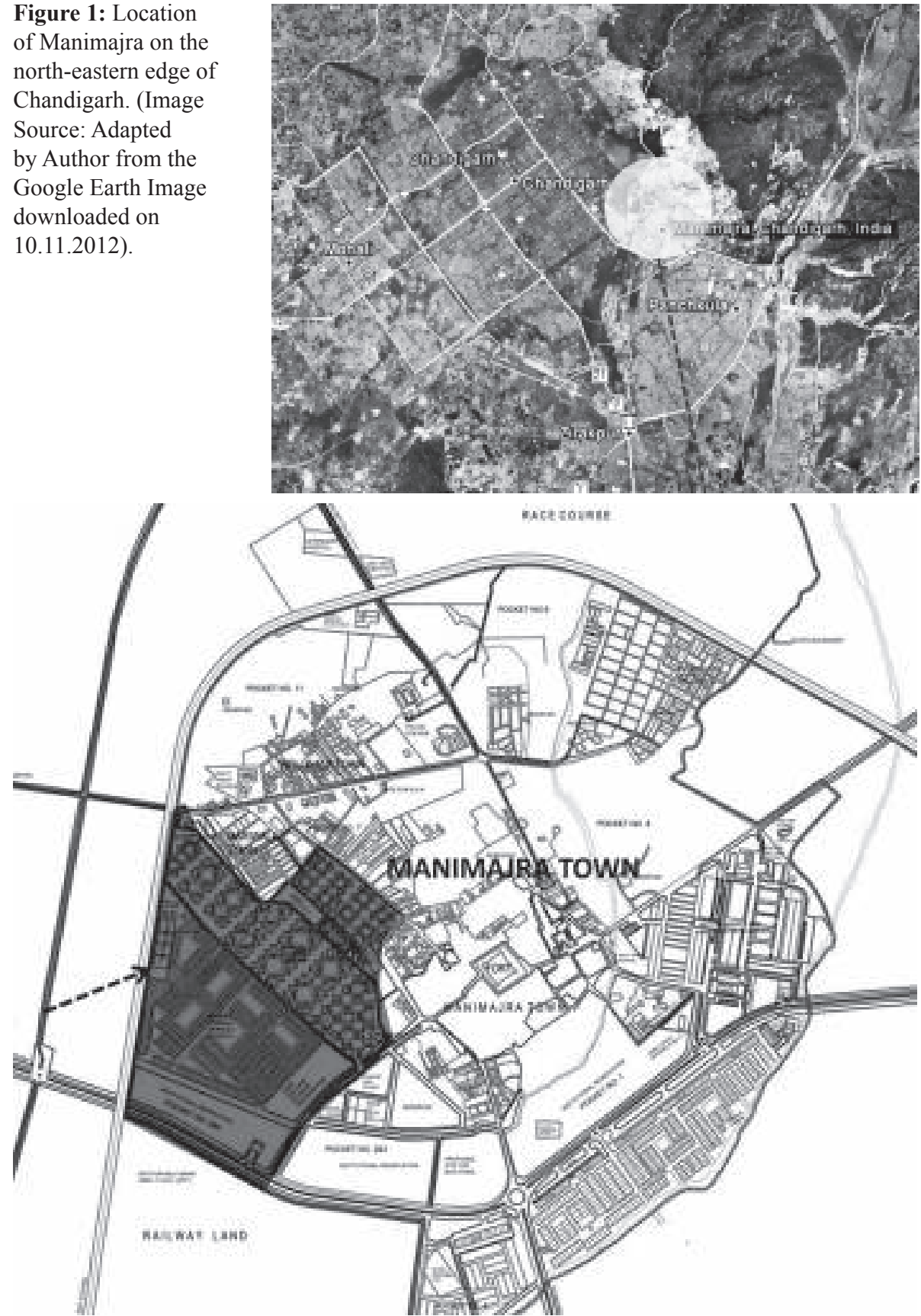

Design Strategies for Reorganizing the Public Realm of

a Neighbourhood

Unit: The Case of Modern

Housing Complex, Manimajra, Chandigarh

Figure 2: The Modern Housing Complex within the Manimajra town. (Image Source: Base map provided by the Town Planning Department, Chandigarh, adapted by Author). 
Bansal, K.

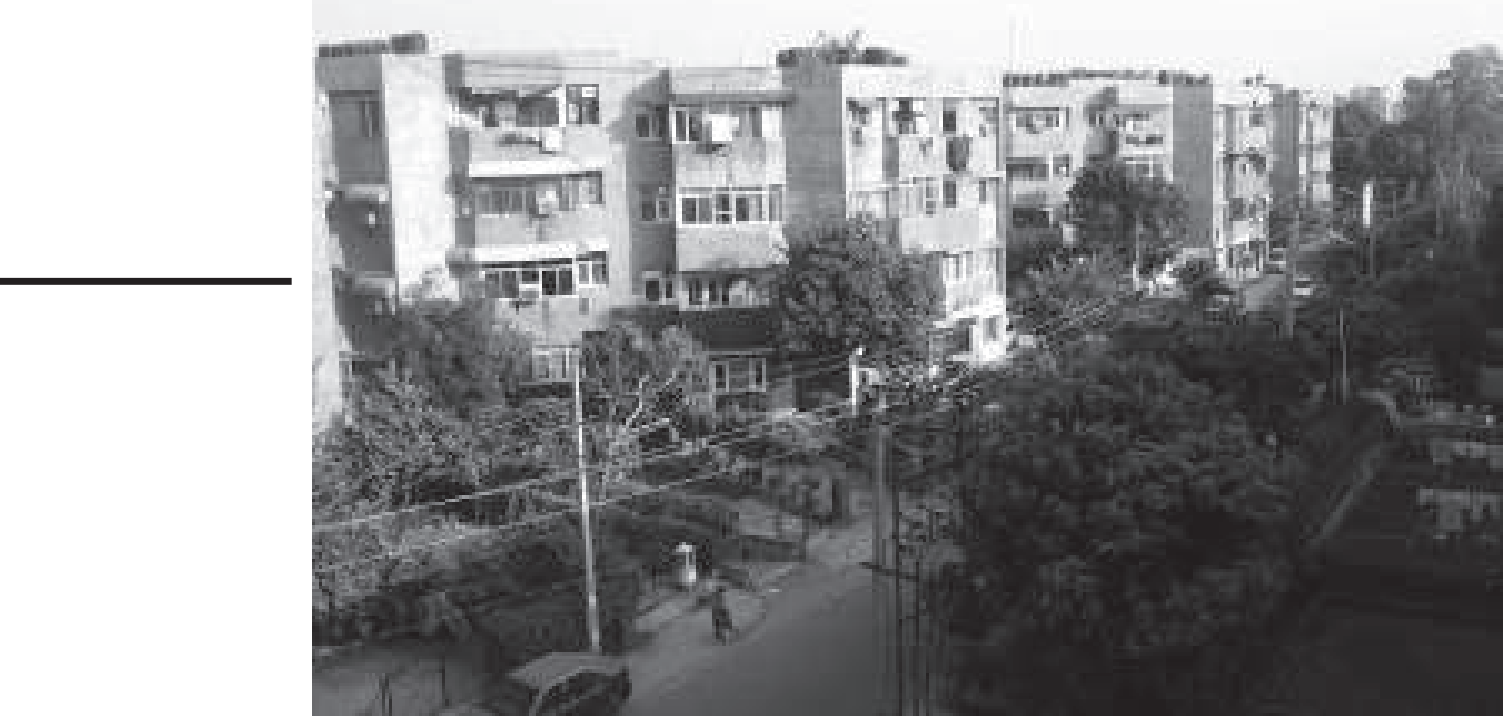

Figure 3: Uniform built form for Category-I to category-IV with exposed concrete rising four storeys high. (Image Source: Author).

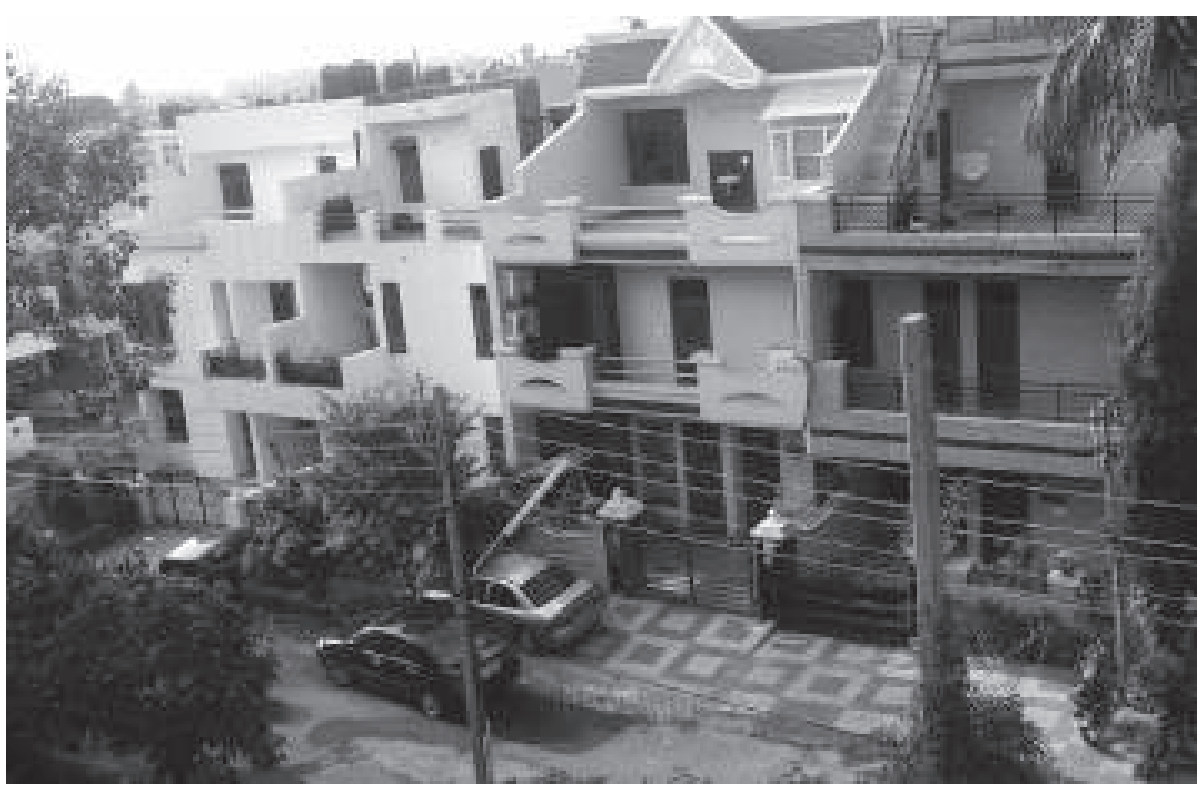

Figure 4: Duplex houses rising 3 storeys with each house having its own facade treatment but uniformity in façade control and size. (Image Source: Author). 
courtyard. All blocks have a uniform architectural with exposed concrete and grit-finished façades (Fig. 3). In the Phase II, where there are duplex type town houses, each individual house has its own architectural expression with a variety of materials and colours but all follow the specified façade controls and height restrictions as levied by the Chandigarh Administration (Fig. 4).

Over the years, the Modern Housing Complex has undergone several transformations, primarily affecting the public realm. The aim of the project was to find ways to improve the public realm and make such existing communities better places to live in. Though the buildings facades - an essential component of the public realm - too have undergone many (illegal) modifications, redressal of the issue was considered to be outside the scope of the project, which focussed primarily on the community facilities, including the shopping centre, circulation areas and, the public open spaces. The survey and analysis of the area was carried out in November-December 2012 with a clear concern to understand the problems and issues that may have emerged due to changing lifestyles, varying needs of users and, of course, the changed transportation modes. The project was analyzed methodologically identifying the existing needs and problems, reviewing the literature and, thus, defining the design goals to give an optimum design solution.

\section{PART ONE: CIRCULATION AND PARKING}

The large part of the study concentrated on understanding the given system of circulation, both vehicular and pedestrian. The findings are described as "The System of Streets", "Parking Provisions" and "Pedestrian Connectivity."

\section{The System of Streets:}

According to the neighbourhood theory, which seeks to protect the residents from the hazards of fast traffic, the major arterial roads and through traffic routes should not pass through a residential neighbourhood, and, thus, should be provided at its boundaries. It also suggests that the interior street pattern should be designed to encourage a quiet, safe, low volume traffic movement to aid preservation of the residential atmosphere. Within the Modern Housing Complex the arterial roads do not intervene through the site (Fig. 5a). Instead, through the sub-arterial roads they feed the collector roads making the neighbourhood safe from the heavy flow of traffic. The housing complex has a hierarchical network of streets as described under:

a. Collector Roads: These introduce the traffic from the main sub-arterial roads into the housing complex. (Fig. 5b) In Phase I and Phase II the collector roads acts as ring roads around the perimeter. They also
Design Strategies

for Reorganizing the Public Realm of

a Neighbourhood

Unit: The Case of Modern

Housing Complex, Manimajra, Chandigarh

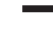




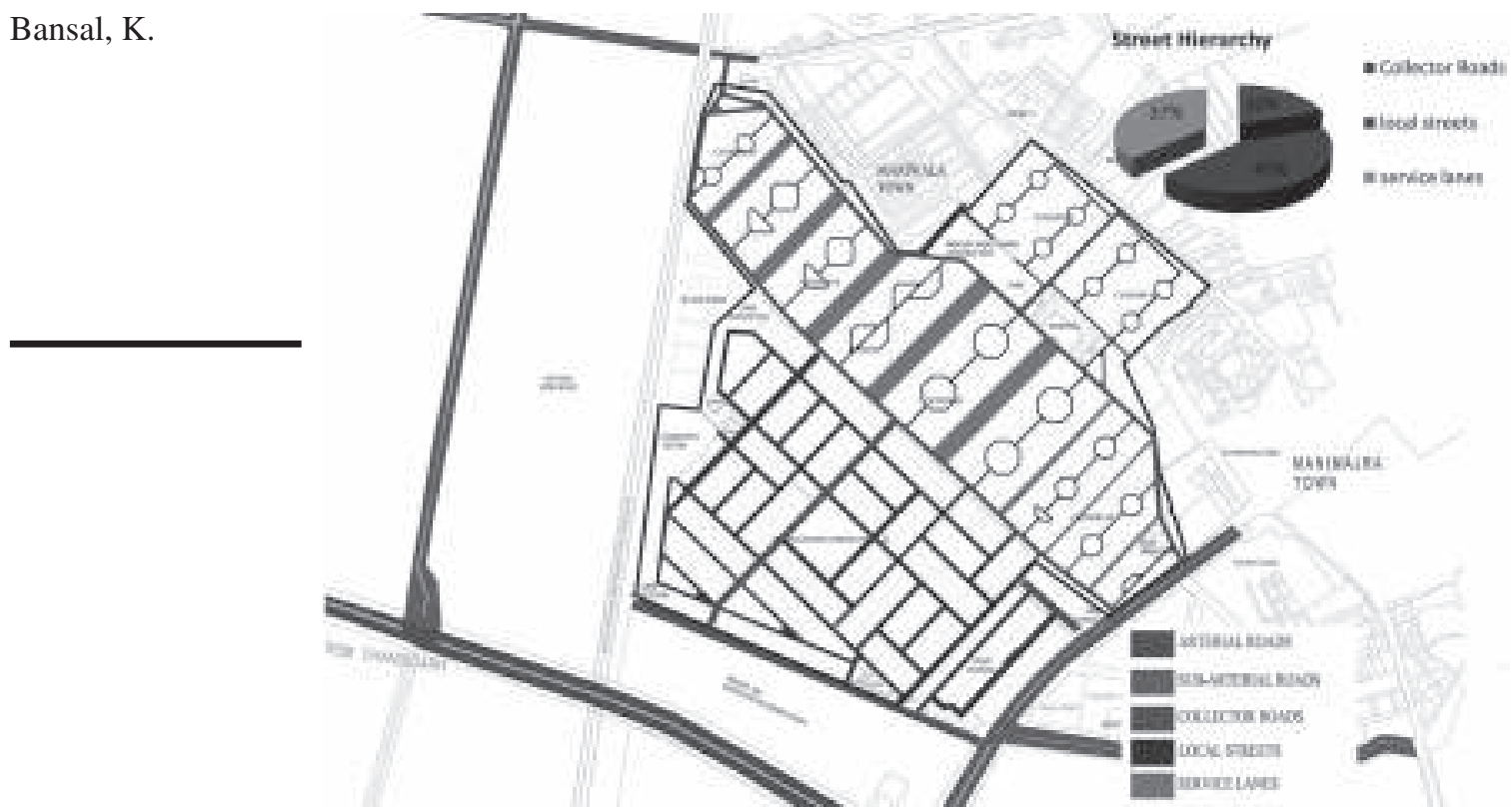

Figure 5a: The street system of the neighborhood (Image Source: Base map from the Town Planning Department, Chandigarh, adapted by Author).

feed the local streets and the service lanes, creating several unsafe, accident-prone road junctions. The character of these roads is defined by the thick vegetation and trees along their length. In Phase III, the Collector Road runs perpendicular to the housing units and meets the ring road of the phase I \& II development. The Collector Road along the shopping complex is marred with a number of street vendors, rickshaw pullers and cars parked along the road side.

b. Local Streets: The Local Streets are fed from the Collector Roads and have a varying right of way from around $7 \mathrm{~m}$ to $14 \mathrm{~m}$ (Fig. $5 \mathrm{c}$ ). They lead to residences and run along the open spaces within the housing clusters. At some places the road widths are as narrow as $4 \mathrm{~m}$, which become too tight for smooth flow of two-way traffic. Very narrow local streets lead to a lot of traffic congestion, especially as large cars and heavy transport vehicles do not get adequate turning radius at the junctions. In Phase I and Phase II the local streets run perpendicular to the housing units. The local streets within a cluster have no direct link to those within the adjoining cluster and, thus, have to be accessed 

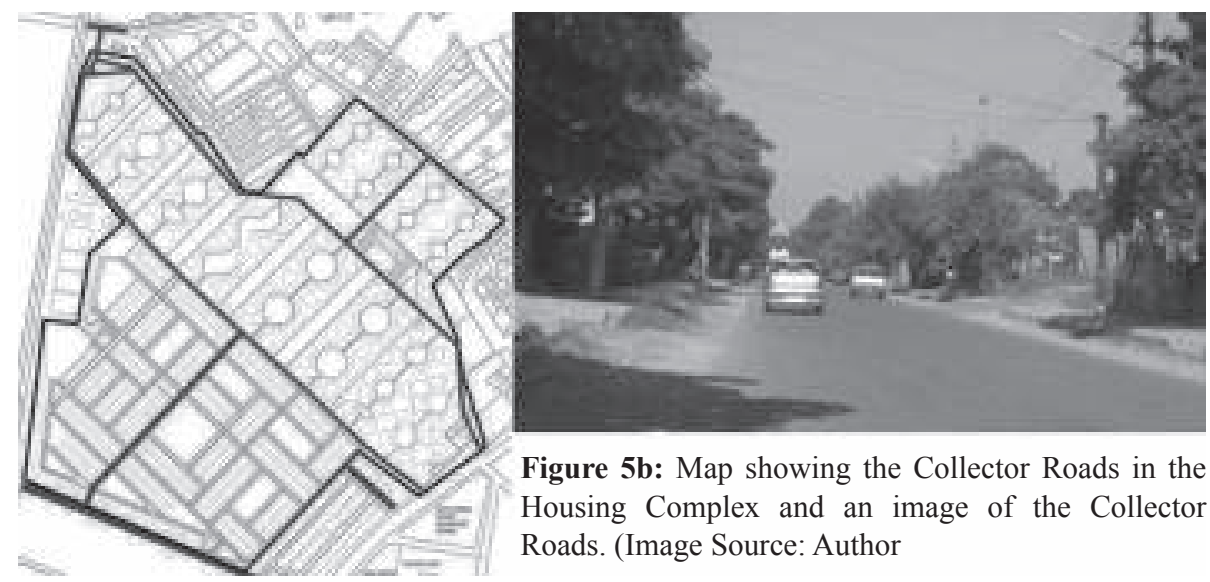

Design Strategies

for Reorganizing the Public Realm of a Neighbourhood Unit: The Case of Modern Housing Complex, Manimajra, Chandigarh

Figure 5b: Map showing the Collector Roads in the Housing Complex and an image of the Collector Roads. (Image Source: Author
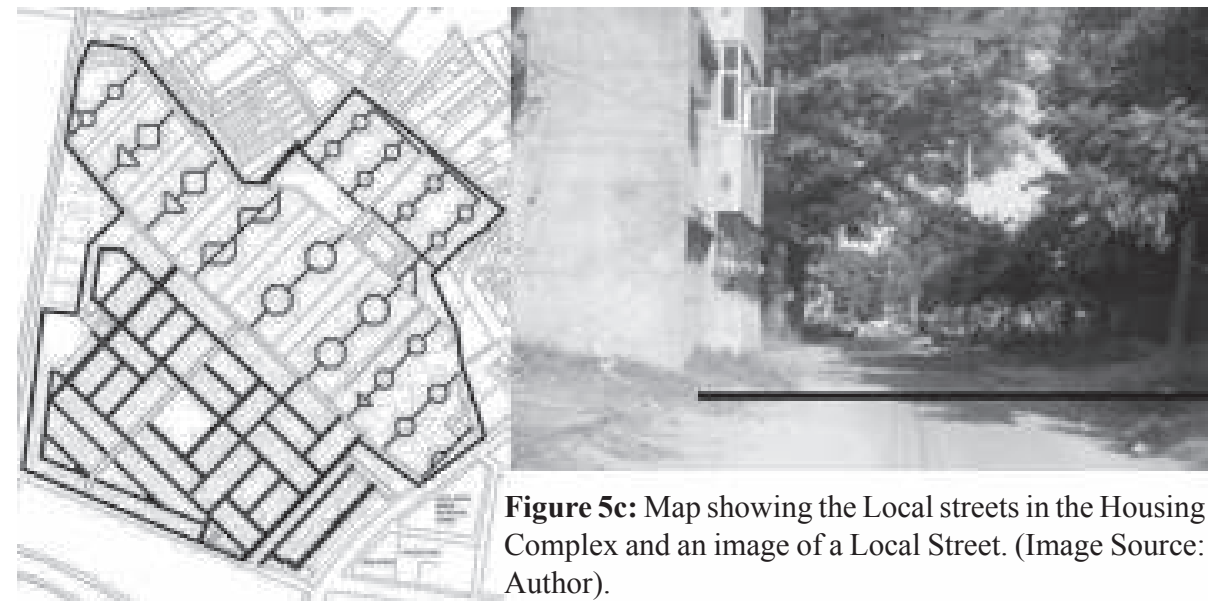

Figure 5c: Map showing the Local streets in the Housing Complex and an image of a Local Street. (Image Source: Author).
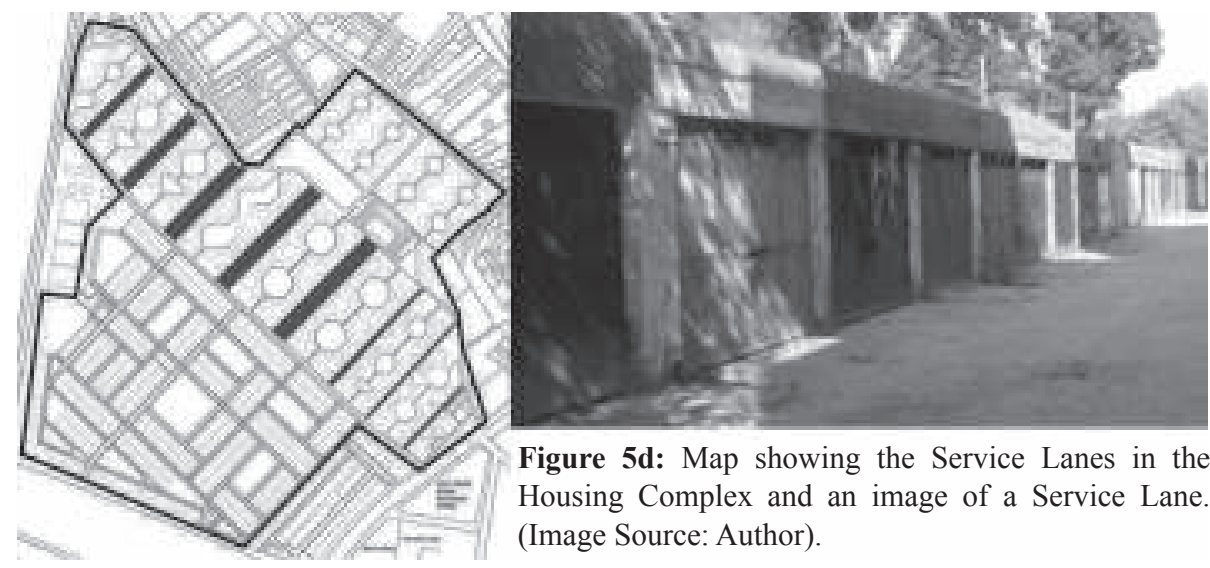

Figure 5d: Map showing the Service Lanes in the Housing Complex and an image of a Service Lane. (Image Source: Author). 
through the Collector Roads on either side. This limitation makes wayfinding very tedious and confusing for the visitor as all building blocks have been made to a standard design and look the same.

c. Service Lanes / Parking Streets: These are the streets which lead to garages allotted along with the housing units. (Fig. 5d) These garages are at a level $2.70 \mathrm{~m}$ below the road and the services lanes run down the ramps from the Collector Roads and give access to the four wheeler and two wheeler garages (Fig. 6). The Service Lanes have no vehicular connection to the Local Streets which lead to residences forming a cul-de-sac type of parking for the housing units. The parking garages are currently not used as the residents do not consider their vehicles to be safe in locations which are neither directly accessible nor visible. The pedestrian connection between the adjoining clusters is through the parking streets/service lanes, which being at a lower level makes it impossible for the disabled to communicate from one group of clusters to the other (Fig. 7). As a result the service lanes / parking streets are only used as through roads rather than serving the purpose for they were designed.

\section{Parking Provisions:}

One of the most crucial issues seen in the study area was that of inadequate and inappropriate parking. When the Complex was planned in 1989, only one out of four residences owned a car. The original plan, thus, provided only 260 car garages for the 480 Category I flats and, 225 car garages the 384Category II flats. Each of the smaller Category III and Category IV flats were provided with garages for two wheelers. In Phase III, the design of the independent houses allowed for one car to be parked within the premises of the house.

However, today many residents of Category I and Category II flats own more than one car; around $75 \%$ and $55 \%$ of the residents of Category III and Category IV respectively own a car in addition to two-wheelers. The result is an acute shortfall of parking within the residential area, which has further led to the (mis)use of all parks, most of the open spaces, and roadsides into parking spaces, severely impacting the public realm of the area (Fig. 8). As already stated, the other problem that was encountered was that of safety of vehicles and the residents. Since the vehicles are expected to be parked away from the residences and the physical link between the two is neither safe nor convenient, people are reluctant to use the designated parking spaces, further increasing the parking menace. 

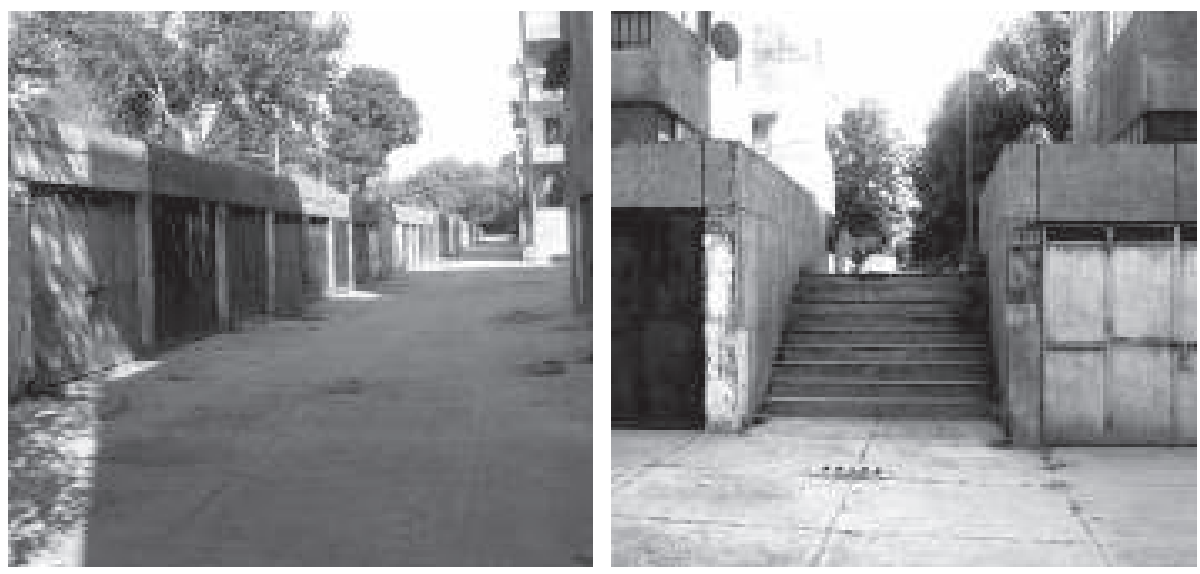

Design Strategies

for Reorganizing the Public Realm of a Neighbourhood

Unit: The Case of Modern

Housing Complex, Manimajra, Chandigarh

Figure 6 \& 7: Four wheeler parking garages along the service lanes at the Modern Housing Complex, Chandigarh. (Image Source: Author).

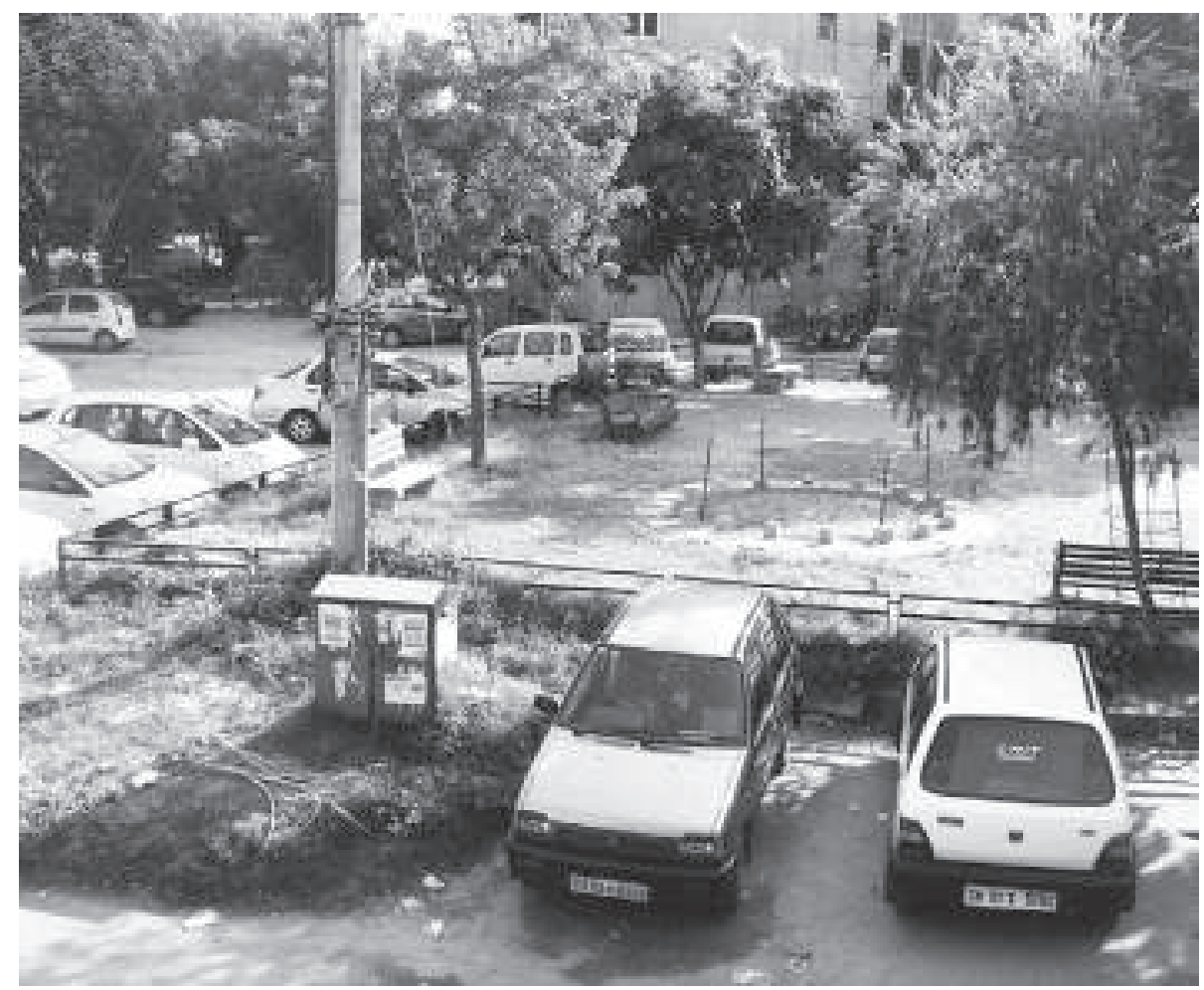

Figure 8: Parkettes being used as parking spaces rather than public interaction spaces . (Image Source: Author). 


\section{Pedestrian Connectivity:}

Since a neighbourhood is conceived as a safe, pedestrian unit, its extent is governed by the comfortable walking distance from the dwelling unit to the elementary school and shopping centre, which are expected to be centrally located. This walking distance, as considered by Clarence Perry is a $1 / 4$ mile, resulting in a neighbourhood of $1 / 4$ mile radius.

Although the overall size of the Modern Housing Complex is comparable to Perry's ideal, the entire neighbourhood lacks pedestrian connectivity between various clusters, a situation which leads to strong conflict between pedestrian and vehicular movement besides making it unsafe, especially children and the elderly. The introvert planning does not help in making the clusters safe as the pedestrians are in constant struggle with the vehicular movement. Absence of such safe connections makes the residents reluctant to send their children to the parks, or from one residential cluster to the other. The lack of pedestrian connectivity from the residential clusters to the shopping centre forces people to use their vehicles even for their daily shopping, a situation which adds to the traffic and parking woes.

Currently the local transport has its halt on the Collector Road near the shopping complex located almost in the centre of the neighbourhood. Lack of pedestrian connections from these Bus Stops poses further difficulty for the residents. There are no designated Bus Shelters, which makes it inconvenient for the people to wait for the bus.

\section{PART TWO: PUBLIC OPEN SPACES}

Open spaces were considered as areas of prime concern as their efficient and appropriate planning helps to considerably improve the public realm. A variety of Public Open Spaces can be found in the Modern Housing Complex (Fig. 9). The typology of these spaces is given below:

1. Vacant Land: These are two huge belts of vacant land that border the two sides of the neighborhood, the North-western edge and the South-western edge reserved for commercial/ institutional purpose in the future. As such, both pockets lie outside the actual Action Area and the scope of the present study.

2. Parks: These are the larger rectangular spaces mostly found in the plotted development of the Phase III. These parks are well maintained and serve their purpose of public interaction within the housing clusters (Fig.10). 


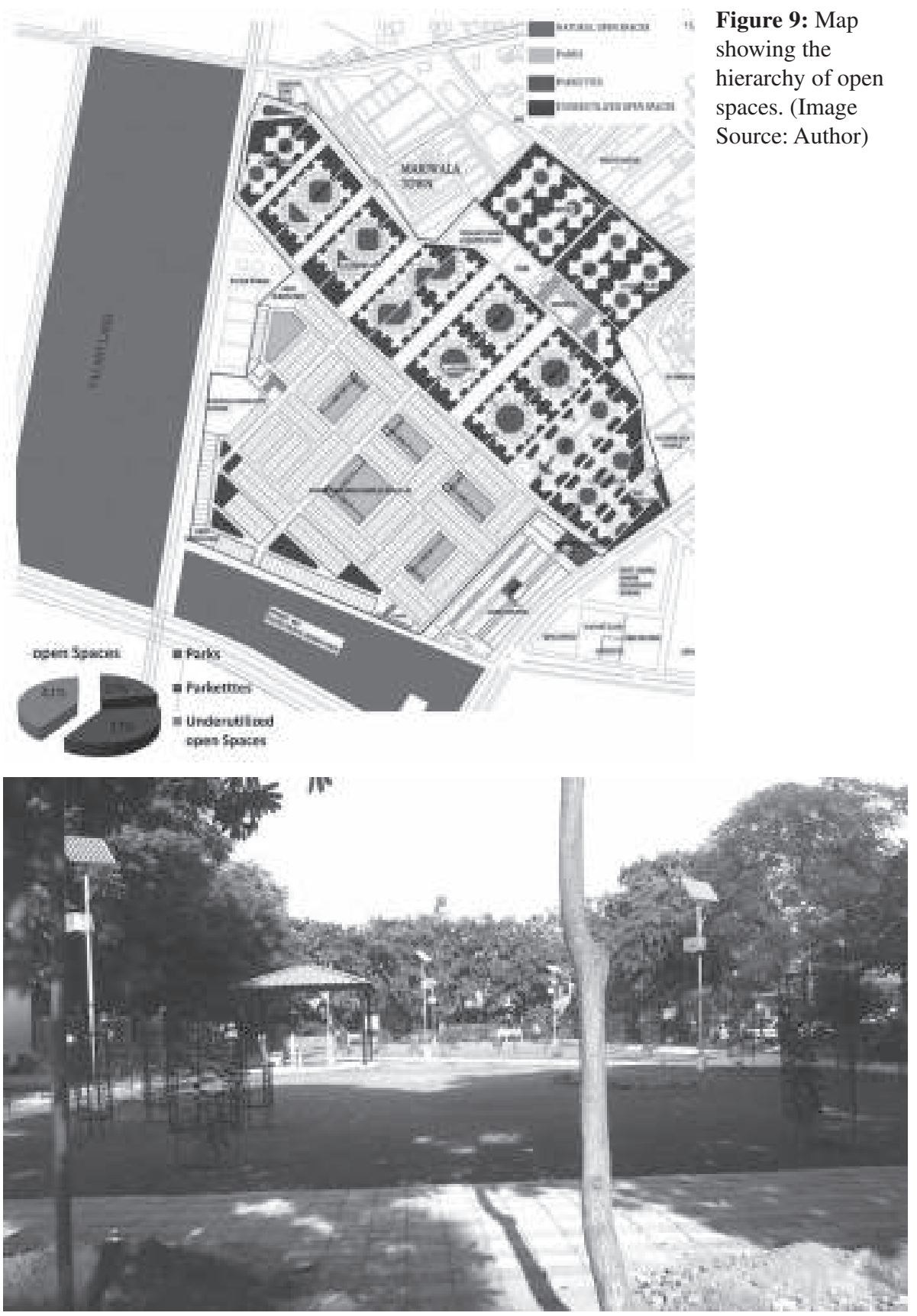

Design Strategies for Reorganizing the Public Realm of a Neighbourhood Unit: The Case of Modern Housing Complex, Manimajra, Chandigarh

Figure 10: A well maintained park amidst the duplex houses aids for lively community interaction. (Image Source: Author). 


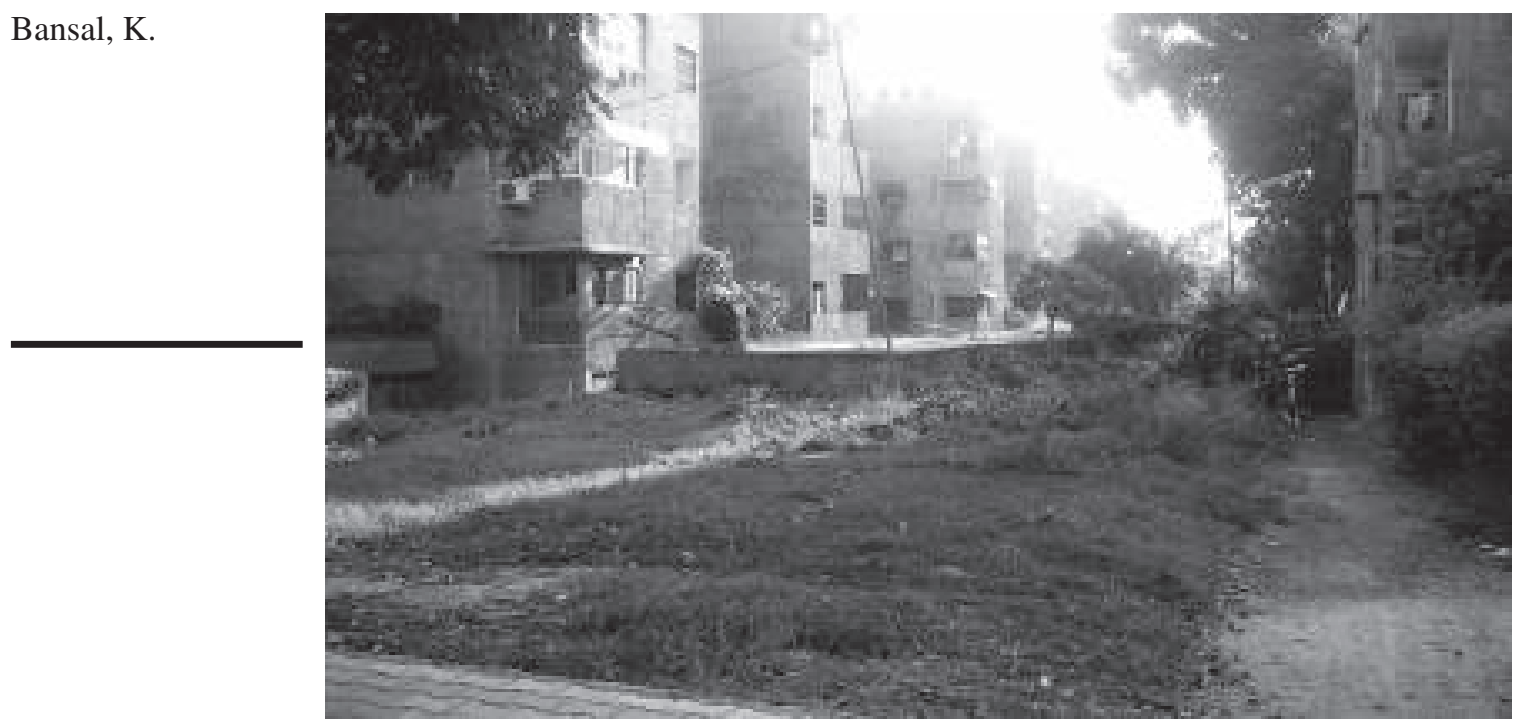

Figure 11: Underutilized spaces within the territory of the complex which are sites that are either used for parking or promote antisocial activities. (Image Source: Author).

They are lively and active in the evenings and residents view them as safe and pleasant spaces where the children can play, the young can jog and stroll for physical fitness and the elderly can sit and chat for long hours.

3. Parkettes: The 'Parkettes' are smaller sized parks, mostly found in the higher-density Phase I and Phase II of the complex. These parkettes are central spaces of each cluster four residential towers. The shape is either octagonal or triangular, depending upon the configuration of the cluster. Though each cluster has been well conceived to have its own public space, but the connection between the various parkettes is experienced via an uncomfortable negotiation through conflicting vehicular and pedestrian systems. Today, these parkettes are not being used for their desired purpose because of poor maintenance and because of the acute shortage of parking spaces which has forced them to be used as parking lots instead of spaces meant for public interaction (Fig. 8).

4. Underutilized Spaces: These are the neglected and ill-maintained spaces within a neighborhood that may have become symbols of decay and despair, yet provide an opportunity for reshaping urban neighborhoods by putting them to some potential use. Their location, size, shape and physical 
condition determine their potential of future use in a development. The Modern Housing Complex has a fair percentage of open spaces which have not been assigned any purpose. These have been increasingly converted into parking spaces and garbage dumps, with uncontrolled vegetative growth that promotes various forms of antisocial activities - all which adversely affect the livability of the entire neighborhood (Fig. 11). The group includes the roadsides that have inconsistent tree plantation, bad paving, no street furniture, not only spoiling the street's imagebility but also hindering their role as spaces for casual public interactions. All these spaces need to be put to some use for them to contribute to the public realm and help in making the neighborhoods a more safe and livable place.
Design Strategies

for Reorganizing the Public Realm of

a Neighbourhood

Unit: The Case of Modern

Housing Complex, Manimajra, Chandigarh

\section{PART THREE: COMMUNITY FACILITIES}

An ideal neighbourhood unit is expected to include a healthy provision and arrangement of all community facilities - a very significant component that adds vitality to the Public Realm shared by the residents. Such facilities primarily include the primary school, a shopping centre, spaces for outdoor recreation, a community centre, a sports centre, etc. The neighborhood concept dictates that the community facilities should be well connected at a walkable distance from all residences.

The land use plan of the Modern Housing Complex very clearly indicates the presence of community facilities within the area. There is a shopping complex, a temple, a dispensary, a school and a community centre within the neighborhood (Fig. 12). However, instead of occupying a central position within the neighbourhood, the community centre is located at one corner of the site which is very difficult to access by most residents and also creates a lot of public nuisance when it is active. Similarly, other community facilities such as the health centre and the shopping centre are located in a scattered manner at various corners of the site. The complete absence of guiding signage or distinctive built form makes it difficult for the residents to locate them, as a result which these are hardly used. The area in front of the Temple Precinct and the open spaces alongside it are, at the moment, lifeless entities, but have the potential for development for good community interaction.

Of utmost importance here is the Shopping Centre, being the one facility used by all residents on a daily, and, even a bi-daily basis. This facility was, thus, taken up as part of the exercise for improvement of the area's public realm. The location of the shopping complex, it was found, is centred within the area comprising Phase I and Phase II, but becomes inaccessible from the Phase III, especially due to the absence of pedestrian connection. 


Bansal, K.

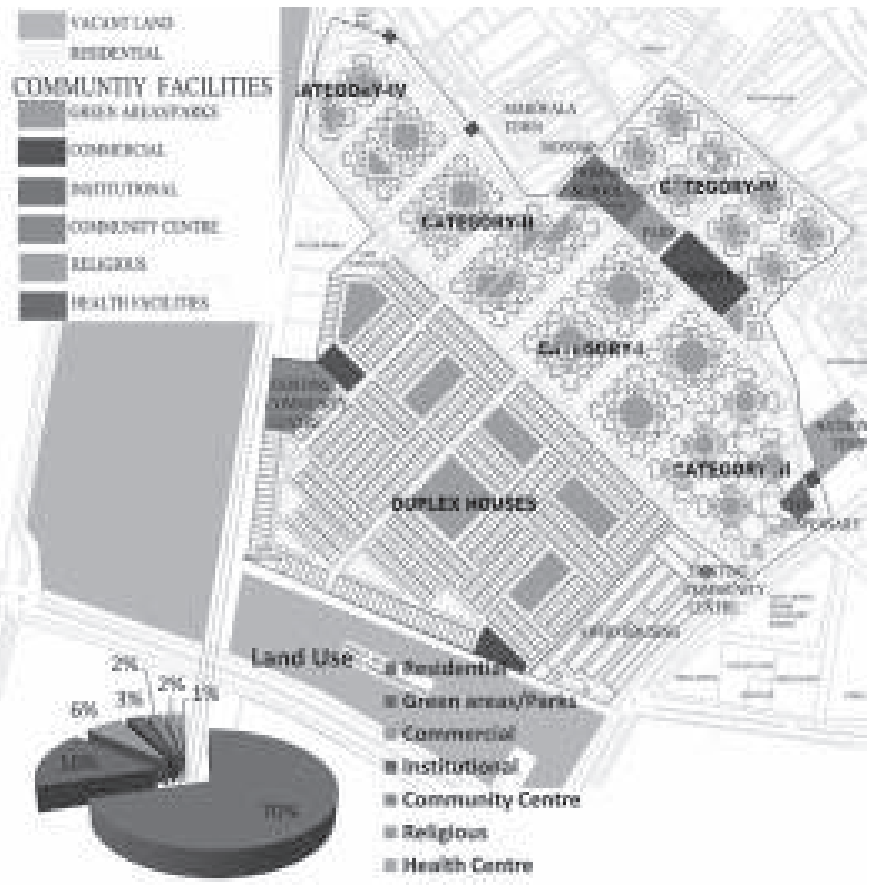

Figure 12: Land use map of the Modern Housing Complex along with percent wise distribution of various functions within the study area. (Image Source: Author)

\section{IDENTIFYING THE ISSUES AND DESIGN CHALLENGES}

The Issues and Design Challenges identified through the surveys have been summed up below under the same heads as used to present survey findings:

\section{Circulation and Parking:}

a. Poor design and inappropriate utilization of various categories of streets and their inter-connectivity, including unmanaged, accidentprone junctions on the Collector Roads.

b. Non-utilisation of parking garages and acute shortage of parking spaces

c. Absence of a safe, barrier-free, comfortable, convenient and integrated pedestrian circulation system to connect various parts of the complex

\section{The Public Open Spaces:}

a. Huge chunks of underutilised, unmaintained spaces, negatively impacting the livability of the Complex.

b. Many Parks and almost all the Parkettes and Roadsides are not utilized as public spaces, but for parking and other dead functions depriving the children and the elderly of safe places for play and leisure activity. 


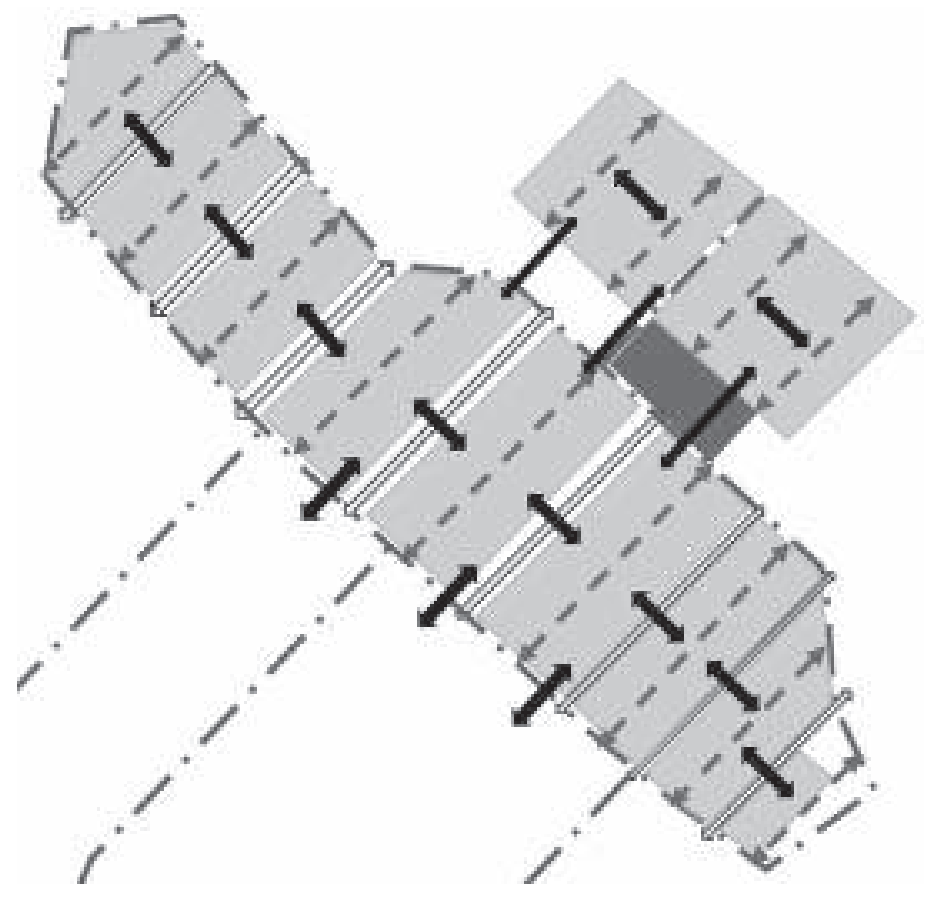

Figure 13:

Conceptual sketch showing strategies that will be adopted to create permeability within the neighbourhood. (Image Source: Author)
Design Strategies

for Reorganizing the Public Realm of

a Neighbourhood

Unit: The Case of Modern

Housing Complex, Manimajra, Chandigarh

\section{Community Facilities:}

a. Scattered location and poor built form of community facilities

b. Shopping areas mostly dead and inactive because of inappropriate location and lack of safe and convenient pedestrian connections.

c. One of the major design challenges, thus, would include restoration and revitalisation of community facilities, including providing improved pedestrian access through enhanced longitudinal and transverse permeability within the neighbourhood (Fig. 13)

\section{DETERMINING THE DESIGN GOALS}

The issues and challenges listed above further aided in determining key Design Goals, which while utilising the existing infrastructure to the maximum, seek to improve the Public Realm and enhance the Livability of the Action Area. The Design Goals were articulated as:

1. Improving Circulation, Accessibility Parking Facilities: To be a truly conflict-free and universally accessible place, characterised by a strong 
focus on public transit, walking and cycling, as well as adopting the positive attributes of streets, treating them as areas of public realm. This may also be interpreted as creation of a pedestrian dominated environment articulated by an attractive and accessible system of streets and public spaces, and, create a safe, pedestrian friendly environment for the residents that is conducive to good living and enjoyment. Action also needs to be taken to cater to the increased parking needs of residents and reduce the parking menace created on the road sides, parks and open spaces.

2. Improving and Activising Public Open Spaces: To repossess and develop parkland and open space land in a manner through which existing and future residents can best achieve their social and recreation pursuits.

3. Community Enhancement: To develop a strong sense of community through active and integrated public spaces and appropriate community facilities. Community facilities to be rationalized so that they are betterdistributed and accessed by the community.

\section{WORKING OUT THE DESIGN STRATEGIES}

The issues and design goals elaborated above were, ultimately resolved through two major Design Strategies:

1. Restructuring Circulation, Parking and Open Spaces: The first Design Strategy concerns interconnected issues of circulation system, parking and open spaces. It was derived from the goal of creating a legible, efficient and pedestrian-friendly circulation system in the Action Area. The key principles of pedestrian linkage and movement were central to the strategy, as was establishing a thriving community centred on a high quality urban environment. This was achieved by appreciating the relationship between adjoining residential clusters and the linkages between public space. The idea was also to convert the streets into pleasant public spaces which would support a wide range of social and recreational activities. The solution also seeks to restore the original function of the parkettes as safe public parks. Given below is a description of the various interventions proposed:

a. Restricting the vehicular movement to the periphery of the building blocks: This helped in segregating the vehicular and pedestrian traffic, making the clusters safe for walkers and for children to play. It also increased walkability and, therefore, the longitudinal permeability, such that it becomes safe to walk between two clusters within the same block (Fig. 14). 


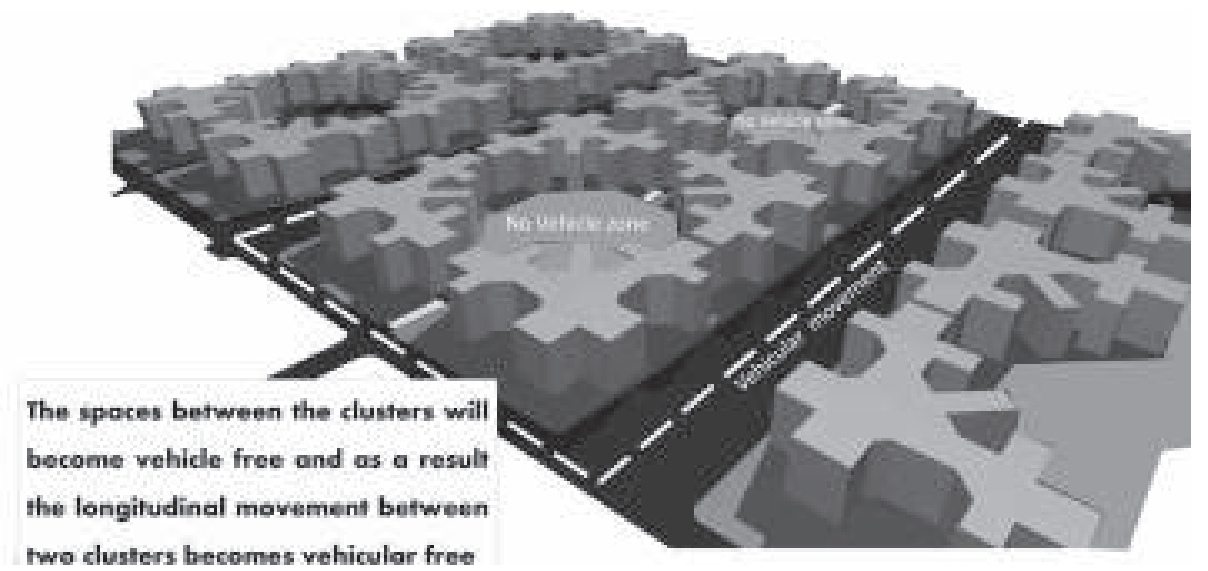

Design Strategies

for Reorganizing the Public Realm of

a Neighbourhood

Unit: The Case of Modern

Housing Complex, Manimajra, Chandigarh

Figure 14: Proposed circulation pattern adopted for segregating Vehicular and Pedestrian movement. (Image Source: Author).

b. Providing adequate parking space to reduce vehicular clutter: The cul-de-sac method was used to force the vehicles to use the provided service lanes. As a result the existing, unutilized parking infrastructure at the lower, $-2.70 \mathrm{~m}$ level would be effectively deployed for its original purpose. An easy solution was found for the parking shortages. It was seen that the existing width of the service lanes was adequate to allow an additional intermediate parking lane for accommodating sufficient number of vehicles to make up much of the existing shortfall. Also, ince the service lanes leading to the smaller two wheeler parking garages were also found to be wide enough for plying of cars, most of the unused space along the two wheeler garages has been converted into car parking

c. Conversion of Local Streets into Pedestrian Paths: All the Local Streets leading to the residential clusters have been converted into pedestrian pathways, integrating them with the green areas so as to create active and attractive public spaces and, simultaneously, increase the longitudinal walkability of the area. The central open spaces will be 'no vehicle zones' and hence will become active and safe greens for safe access by the children and the elderly (Fig. 15).

d. The plan further proposes transverse permeability through connected walkways without any vehicular access. This has been done through 

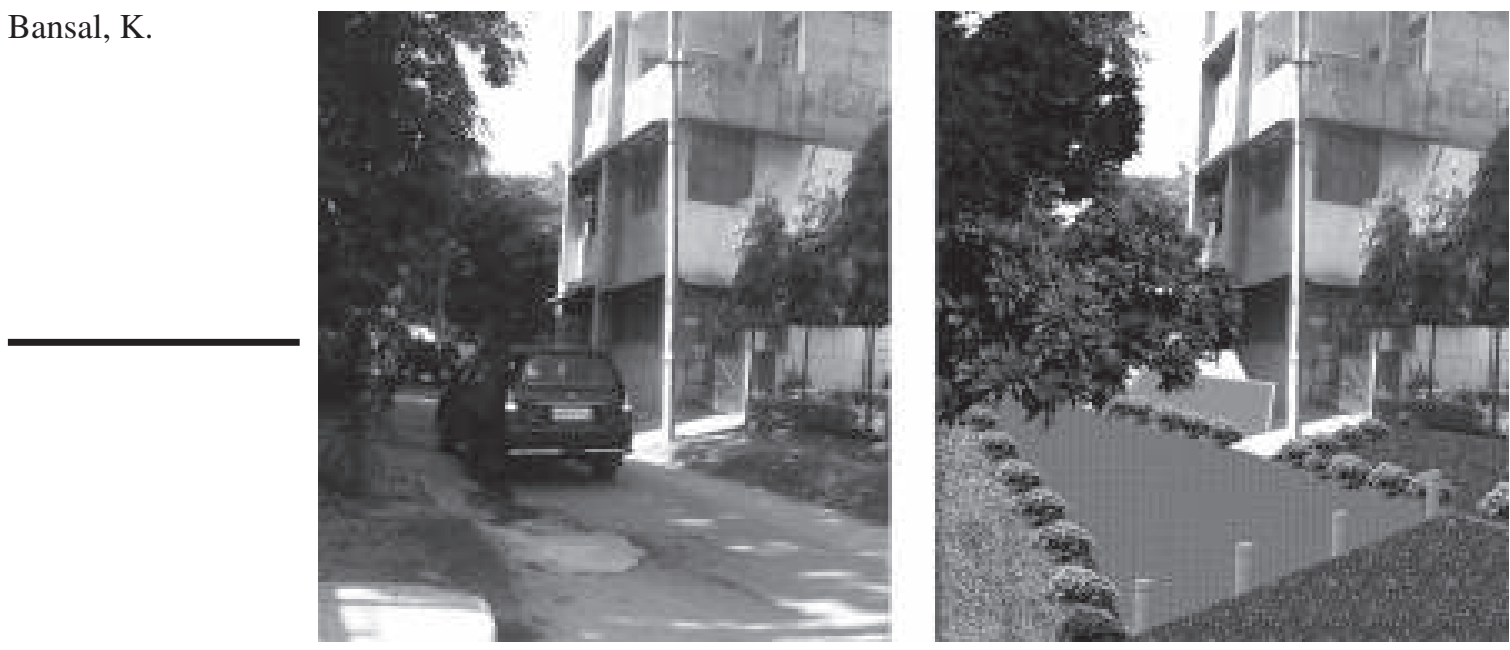

Figure 15: Bollards proposed at the entry of pedestrian lanes to restrict vehicular access. Image Source: Author.

overhead bridges over the service lanes at the pavement level which also makes the neighbourhood disabled friendly (Fig. 16a, 16b).

e. To further contribute to the public realm, the streets and pavements most important and somewhat neglected elements of public realm, are redefined and redesigned. The proposal shows how vegetation, street furniture, benches, etc can enliven these streets to be used as active public spaces (Fig. 17).

2. Revitalising Community Infrastructure: The second Design Strategy was derived from the theory that the most active and public interaction space, i.e., the node comprising all community activities within the neighbourhood, should be at the intersection of major movement axes of a walkable environment. Such should be the placement of the Shopping Centre within the neighbourhood as per Clarence Perry's neighborhood concept as well.

a. With the above in mind, the study identified two existing axes of the scheme, one each in the N-S and the E-W direction, which had the potential to play a vital role in integrating the entire neighborhood (Fig. 18). The design solution proposes a through walkable connection along these axes, and, at the same time, reduce the conflict between 

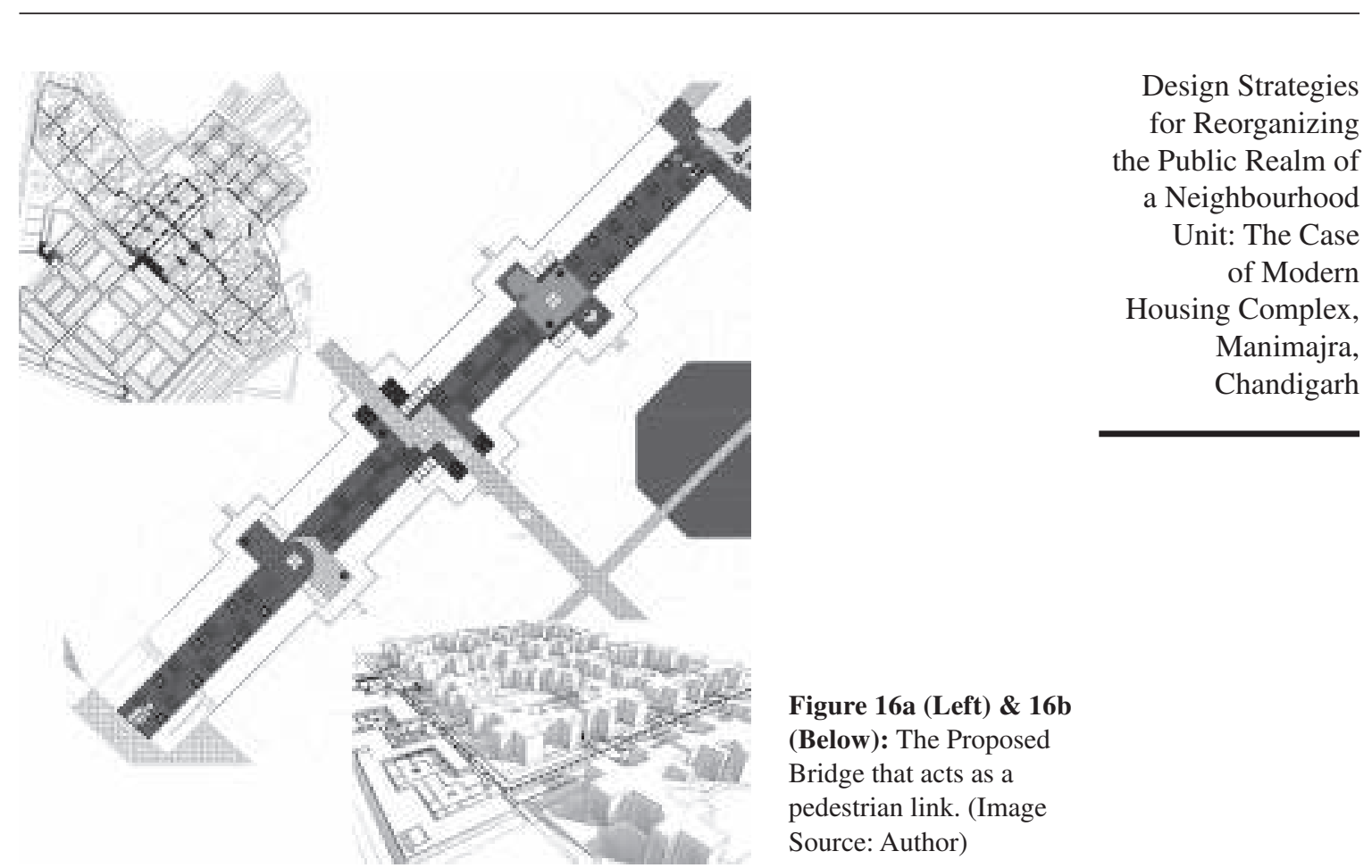

Figure 16a (Left) \& 16b

(Below): The Proposed

Bridge that acts as a pedestrian link. (Image Source: Author)
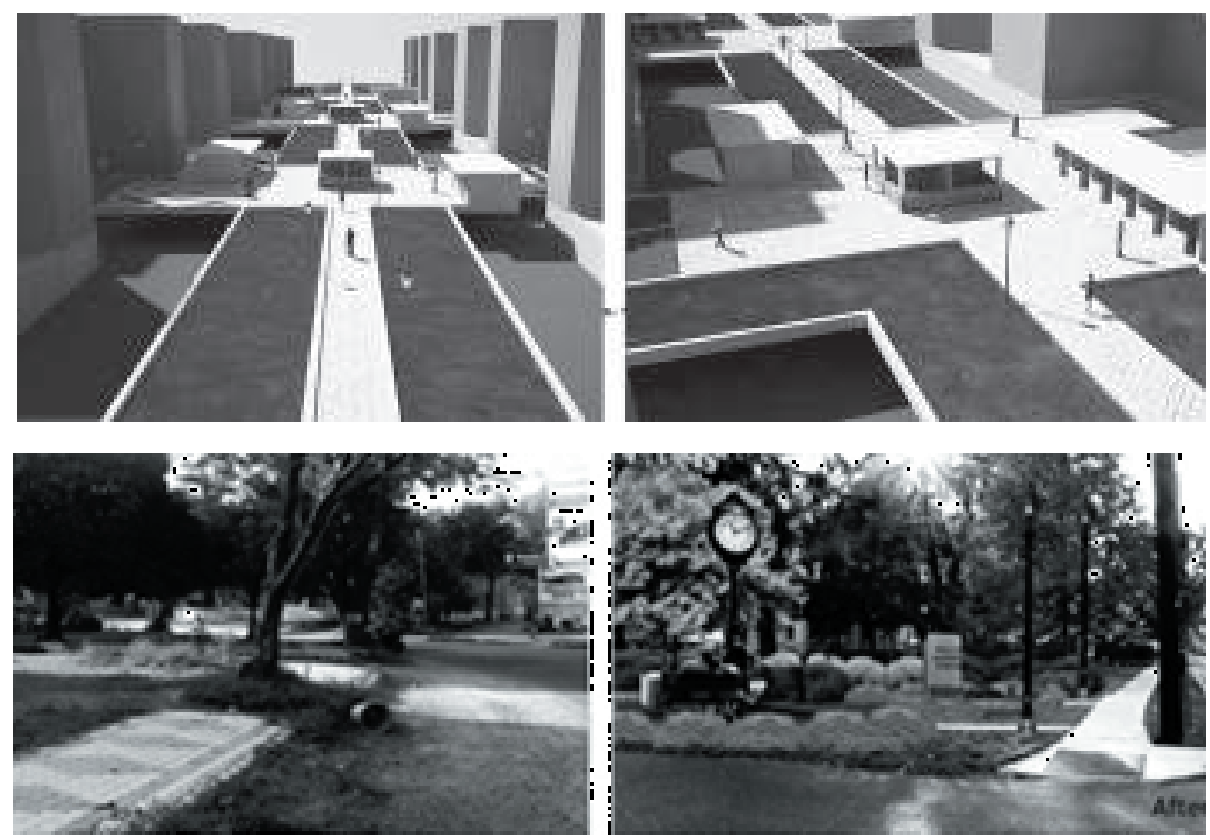

Figure 17 (Above): Proposed streetscape to enliven streets. (Image Source: Author) 


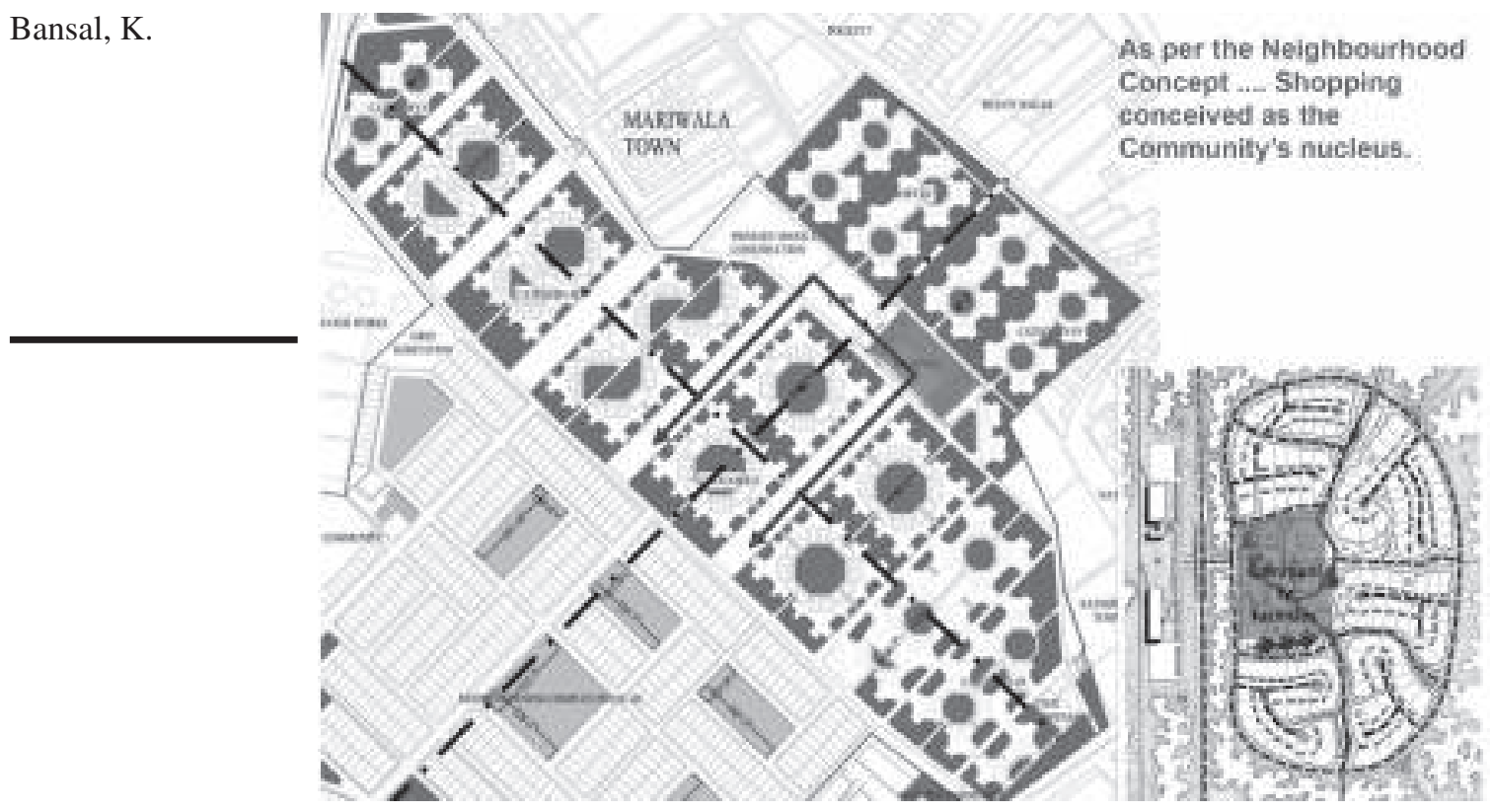

Figure 18: Parts of the road proposed as pedestrian priority zones as a linking interface between the two phases of the Complex. (Image Source: Author)

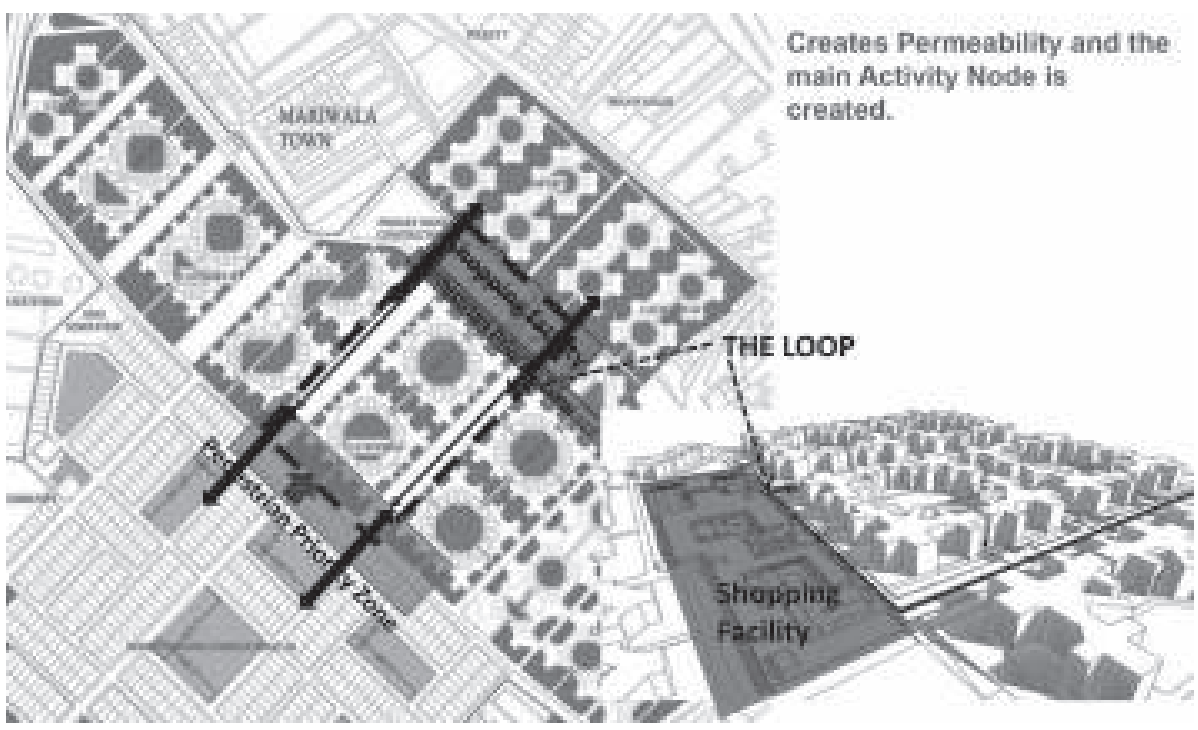

Figure 19: The devised circulation pattern linking the shopping complex. (Image Source: Author) 


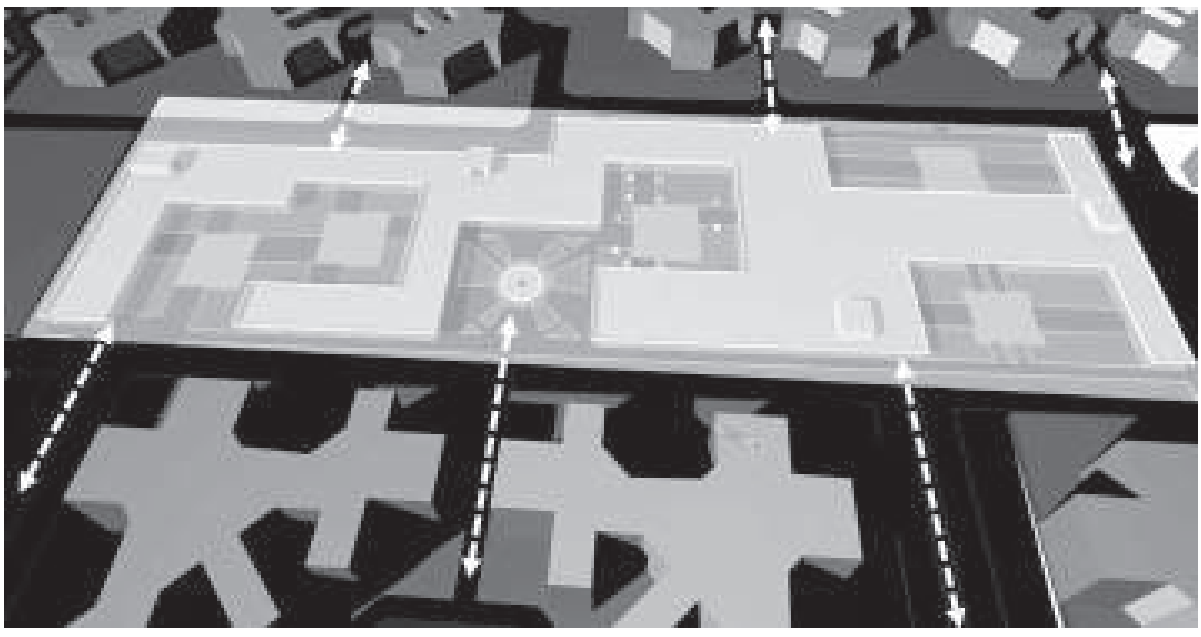

Design Strategies

for Reorganizing the Public Realm of

a Neighbourhood

Unit: The Case of Modern

Housing Complex, Manimajra, Chandigarh

Figure 20: Pedestrian Connections to the shopping complex and its plazas. (Image Source: Author)

the vehicular and pedestrian by creating a walkway above the lower service lanes for carrying the pedestrian across the superblock without vehicular hindrance. The intersection of the Collector Road of Phase III with that of Phase I and Phase II has been converted into a 'pedestrian priority zone' for people to walk through conveniently (Fig. 19).

b. As per the Neighborhood Concept, as also keeping in mind the frequency of its use by the residents, the Shopping Centre is conceived as the nucleus of the scheme. Thus the two main axes, designed as pedestrian walkways, connect the entire community to the commercial facilities. The commercial potential and vitality of the new development is further strengthened through location of small kiosks along the length of the walkway, thereby creating an informal shopping street that will help to enliven the shopping complex and make walking an enriching experience. These pedestrian streets are anchored by a series of large buildings and plazas that provide a substrate for growth and development along the whole street (Figs. 16a, 16b).

c. The shopping complex itself has also been redesigned to integrate the pedestrian connections by taking the parking at the level of the service lanes, i.e., $-2.70 \mathrm{~m}$, and by making the entire loop vehicular free (Fig. 19). Pedestrian connection to the shopping area governs the configuration of the built form as the main aim would be to let the pedestrian flow into a plaza or a covered corridor. (Fig. 20). The built 
Bansal, K.
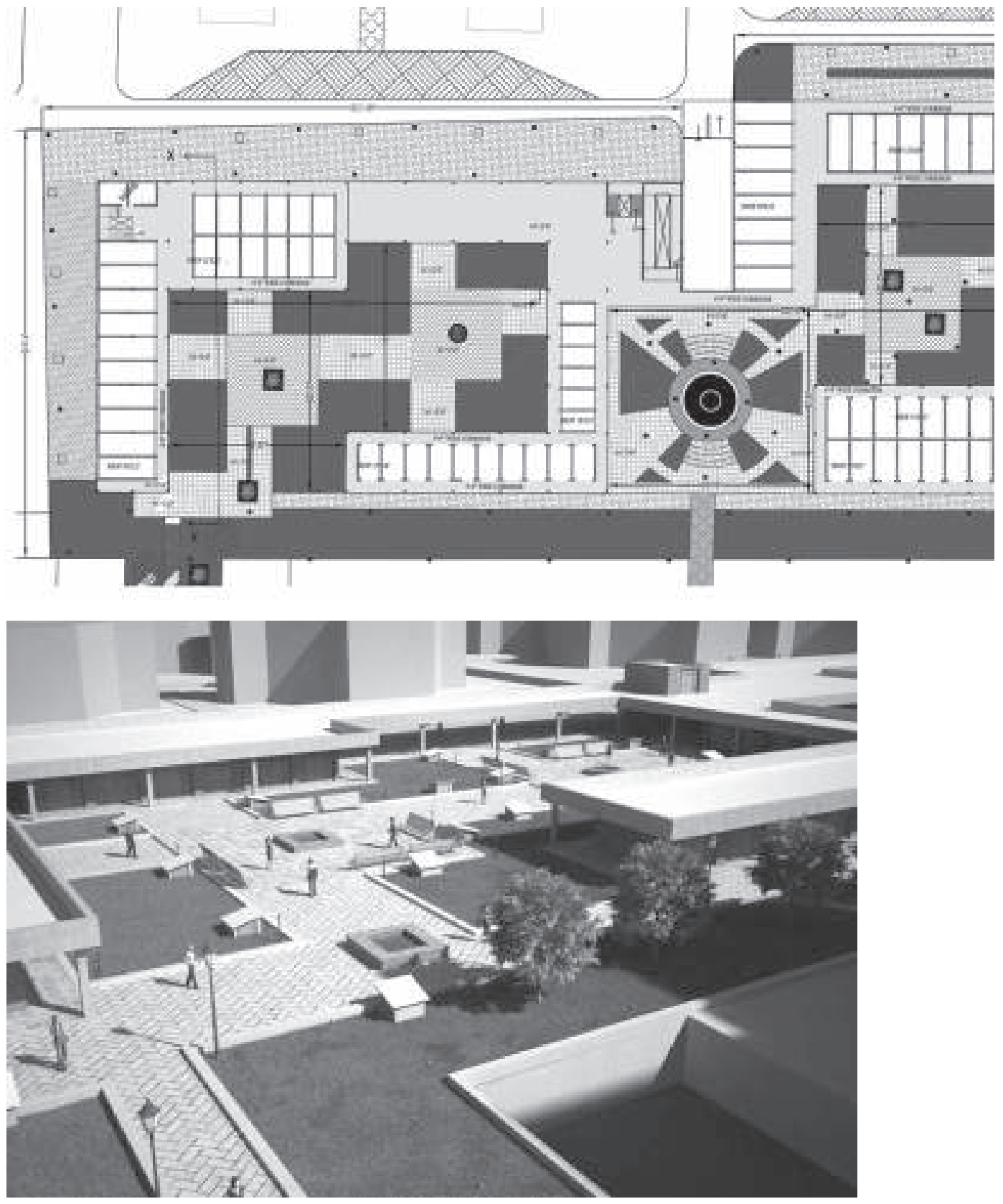

Figure 21a (Top), 21b (Above), 21c (Right): The urban form, public spaces and architectural elements of the shopping complex. (Image Source: Author) 


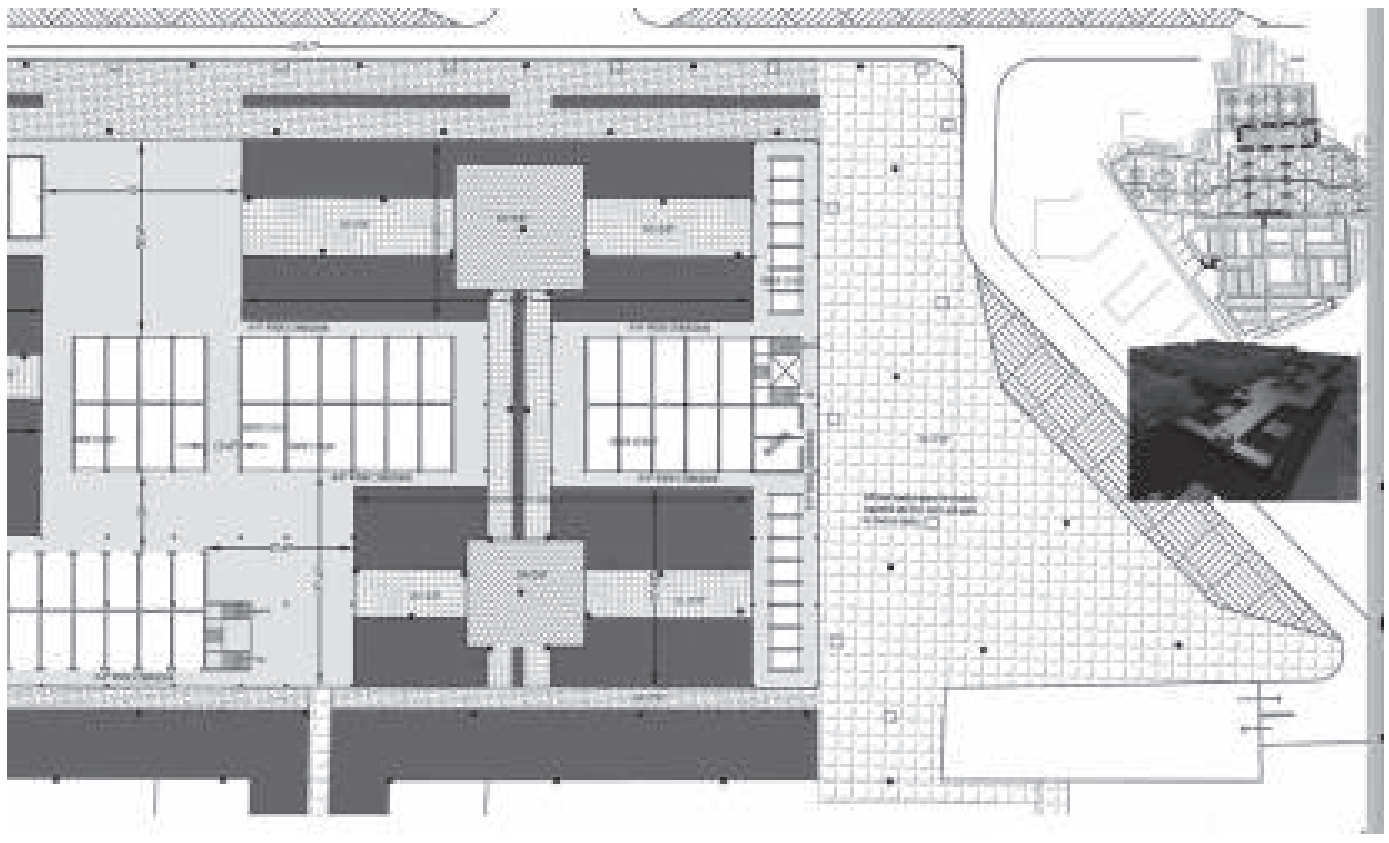

Design Strategies

for Reorganizing the Public Realm of a Neighbourhood Unit: The Case of Modern Housing Complex, Manimajra, Chandigarh

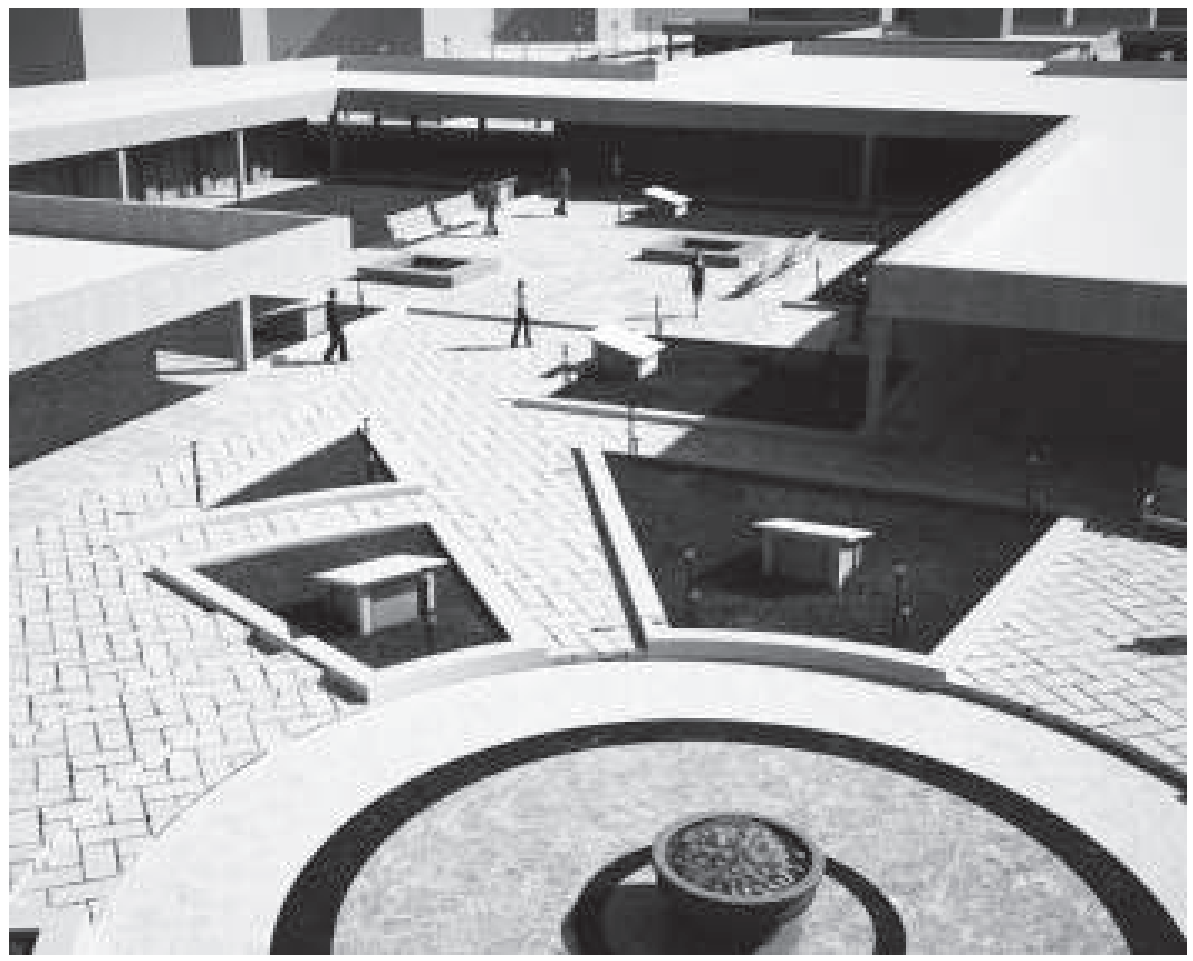


form will respect the neighboring built masses. It would have a lower height and is configured around open plazas which promote social interaction. The design incorporates adequate open and semi-covered spaces that encourage public interaction and, thus, play a great role in improving the quality of life within the neighborhood. The shops are designed such that they open on both ends to increase permeability (Figs. 21a, 21b, 21c).

\section{CONCLUSION}

The physical environment in which people live and operate is the key to adjudge how successfully a neighbourhood works. Living in a safe and vibrant place makes people feel positive and proud of their neighbourhood. On the other hand, living in a place where there is poor security, abandoned vehicles, untidy gardens, unsafe streets and pedestrian connections has the opposite effect. This project has helped to recognize the significance of a Neighbourhood's Public Realm in impacting the quality of life of its residents. It sought to formulate a clear project-based design strategy that would help to enhance quality, functionality, appeal and value within an existing community. The design strategy evolved clearly shows that the quality of open public spaces that promote healthy interaction, the character of the streets that are defined as the primary elements of public realm, safe places for children to play and walkable communities with adequate parking spaces contribute significantly to the well being of the people, ultimately making neighbourhoods more liveable.

\section{REFERENCES}

[1] BOTHWELL, E. S., GINDROZ R., LANG R.E. (1998). Restoring Community through Traditional Neighborhood Design: A Case Study of Diggs Town Public Housing. Housing Policy Debate. Vol-9 Issue 1. pp.89 - 114

[2] EVENSON, N. (1966). Chandigarh. Berkley (CA).University of California Press

[3] DU TOIT ALLSOPP HILLIER. (2004) Fort York Neighbourhood Public Realm Master Plan and Architectural Design Guidelines. Toronto

[4] INDIA. CHANDIGARH HOUSING BOARD. (2012). Detailed map of Modern Housing Complex, Phase I \& Phase II. Chandigarh. Chandigarh Administration.

[5] INDIA. CHANDIGARH ADMINISTRATION TOWN PLANNING DEPARTMENT. Local Planning Area Map Manimajra. Chandigarh. Chandigarh Administration.

[6] INDIA. MINISTRY OF URBAN DEVELOPMENT. TOWN \& COUNTRY PLANNING ORGANISATION (2009). Report on Formulating a Master Plan for Chandigarh. New Delhi

[7] INDIA. MUNICIPAL CORPORATION CHANDIGARH. Chandigarh Master plan Draft 2031. Development Plan of Manimajra. Available from: http://chandigarh.gov.in/cmp2031/ manimajra.pdf. Accessed on 12.12.2012. 
[8] JAMES H. (2010) Head of Neighbourhoods, Successful Neighbourhoods Clean, safe and vibrant places where people are proud to live. Available from: http://www.urbandesigncompendium. co.uk/thrivingpublicrealm. Accaessed on 09.01.2013

[9] LE CORBUSIER (1961). The Master Plan. In ANAND, M.R. (ed.) Chandigarh. Marg. XV(1). Bombay: Marg Publications. pp. 4-24.

[10] LYNCH, K. (1960). The Image of the City. Cambridge, MA: Harvard University Press.

[11] PERRY, C. (1929) The Neighbourhood Unit. In WATSON, D., PLATTUS, A. and SHIBLEY, R. (2011). Time Saver Standards for Urban Design. New Delhi. Tata MsGraw-Hill.

[12] SHAMBHARKAR, R. M. (2008). The Neighbourhood Unit Concept as an Urban Space. ARCHITECTURE - Time Space \& People. p.30-34.

Design Strategies

for Reorganizing the Public Realm of

a Neighbourhood Unit: The Case of Modern Housing Complex, Manimajra, Chandigarh 